\title{
PENGARUH PEMBELAJARAN MELALUI MODEL PROBLEM SOLVING FISIKA TERHADAP HASIL BELAJAR DAN KEMAMPUAN PEMECAHAN MASALAH KELAS X MIPA MAN 1 KOTA BENGKULU
}

\author{
Nia Kurniati ${ }^{1}$, Eko Swistoro ${ }^{2}$, Desy Hanisa Putri $^{3}$ \\ Program Studi S1 Pendidikan Fisika, Jurusan Pendidikan Mipa \\ Fakultas Keguruan dan Ilmu Pendidikan Universitas Bengkulu \\ Jalan Raya Kandang Limun Bengkulu \\ Email: niakurniati003@gmail.com
}

\begin{abstract}
ABSTRAK
Penelitian ini bertujuan untuk menjelaskan pengaruh pembelajaran menggunakan model pembelajaran problem solving fisika terhadap hasil belajar siswa dan kemampuan pemecahan masalah kelas X MIPA di MAN 1 Kota Bengkulu. Jenis penelitian yang digunakan adalah penelitian eksperimen semu (quasi experiment designs) dan penelitian desain pre eksperimen (one group pretest-postest design). Pengambilan sampel berdasarkan teknik sampling purposive yang diperoleh siswa kelas X MIPA 2 ( $\mathrm{N}=37)$ sebagai kelas eksperimen dan siswa kelas X MIPA $3(\mathrm{~N}=38)$ sebagai kelas kontrol. Teknik pengumpulan data menggunakan tes untuk hasil belajar dan kemampuan pemecahan masalah. Berdasarkan hasil analisis Uji-T dua sampel independen melalui nilai rata-rata posttest hasil belajar yaitu $t_{\text {hitung }}>t_{\text {tabel }}(2,47>1,99)$, sedangkan hasil analisis deskriptif kemampuan pemecahan masalah melalui nilai rata-rata (posttest KPM - pretest KPM) menghasilkan 63,5. Disimpulkan bahwa terdapat pengaruh pembelajaran menggunakan model problem solving fisika terhadap hasil belajar dan kemampuan pemecahan masalah
\end{abstract}

Kata kunci: Model Problem Solving Fisika, Hasil Belajar, Kemampuan Pemecahan Masalah

\begin{abstract}
This study was aimed to examine the effect of physic problem solving learning model to students' learning outcomes and problem-solving abilities of students grade X MIPA in MAN 1 Bengkulu City. This research used a quasi experimental design with nonequivalent control group design and a pre experimental designs with one group pretest-postest design. The sampling technique used purposive sampling which conducted grade X MIPA $2(\mathrm{~N}=37)$ as experiment class and grade X MIPA $3(\mathrm{~N}=38)$ as control class. The data collected by a test for learning outcomes and problem-solving abilities. Based on the analysis for the two independent samples $t$ test is with learning outcomes posttest $t_{\text {hitung }}$ greater than $t_{\text {tabel }}(2,47>1,99)$ and than descriptive analysis for problem-solving abilities with ( KPM posttest - KPM pretest) is 63,5. In conclusion there is the effect of the application of problem solving physic learning model to learning outcomes and students' problem-solving abilities of grade X MIPA of MAN 1 Bengkulu City.
\end{abstract}

Keywords : Problem Solving Physic Model, Learning Outcomes, Problem Solving Ability.

\section{PENDAHULUAN}

Menurut Bascones (1985) dan Oman (1997) bahwa pembelajaran fisika yang baik merupakan pembelajaran fisika yang sama dengan mengembangkan kemampuan pemecahan masalah dan masalah tersebut dapat untuk diselesaikan[1]. Siswa diajak untuk mampu memahami berbagai gejala dan permasalahan, berpikir, menganalisa serta mampu memecahkan masalah fisika. Larkin (1979) menyatakan bahwa walaupun kebanyakan siswa dapat dengan mudah menerima pengetahuan tentang fisika, tetapi sukar mengaplikasi pengetahuan tersebut dalam menyelesaikan masalah[1]. Hoellwarth, Moelter, dan Knight (2005) mengatakan juga bahwa pembelajaran di kelas cenderung menekankan hanya pada penguasaan konsep fisika namun mengesampingkan kemampuan pemecahan masalah fisika. 
Padahal pembelajaran di kelas diharapkan tidak hanya mampu dalam menguasai konsep tetapi mampu memecahkan masalah fisika dari konsep yang diterapkan ${ }^{\text {[2]. }}$

Hasil wawancara dengan guru fisika kelas X MIPA siswa masih kurang dilatih dalam menerapkan pembelajaran pemecahan masalah. Kemampuan pemecahan masalah yang diterapkan oleh siswa hanya sebatas menuliskan diketahui, ditanya, dan dijawab, namun untuk kemampuan pemecahan masalah yang kompleks lagi siswa belum menerapkannya, salah satunya seperti alasan memilih konsep dasar yang digunakan untuk memecahkan suatu masalah

Menurut Johnson hasil belajar diharapkan menjadi lebih bermakna bagi siswa melalui kemampuan pemecahan masalah[3]. Pembelajaran pemecahan masalah (problem solving) berdasarkan langkah-langkah model problem solving fisika yang dikembangkan oleh (Warimun, 2010) dapat menjadi alternatif untuk meningkatkan hasil belajar dan kemampuan pemecahan masalah siswa tersebut.

Model pembelajaran problem solving fisika yang berlandaskan pada paradigma kontruktivistik tersebut relatif tepat diacu sebagai alternatif model pembelajaran yang inovatif. Pembelajaran dengan menggunakan model problem solving fisika melibatkan siswa aktif dalam memecahkan masalah dan menitik beratkan agar siswa mampu mengutarakan tujuan, menganalisa data, mengemukakan pendapat dan memberi keputusan ketika menghadapi suatu permasalahan di dalam proses pembelajaran fisika, selain itu juga membimbing siswa menjadi problem solver yang berkompeten[4].

Beberapa penelitian yang mendukung dari (Warimun, 2014) dan (Warimun, 2012) membuktikan bahwa dengan pembelajaran dengan menggunakan model problem solving fisika dapat terjadi peningkatan pemahaman konsep dan kemampuan problem solving fisika pada topik Listrik dan Optika. Penelitian ini menggunakan model problem solving fisika yang diujicobakan pada materi Usaha dan Energi. Konsep Usaha dan Energi dipilih karena pada materi tersebut mendukung pembelajaran dengan menggunakan model problem solving fisika.

Berdasarkan uraian diatas, penulis melakukan penelitian untuk mengetahui pengaruh pembelajaran menggunakan model problem solving fisika terhadap hasil belajar dan kemampuan pemecahan masalah, sehingga dilakukan penelitian dengan judul "Pengaruh Pembelajaran Melalui Model Problem Solving Fisika Terhadap Hasil Belajar dan Kemampuan Pemecahan Masalah Siswa Kelas X IPA MAN 1 Kota Bengkulu”.

\section{METODE PENELITIAN}

Jenis penelitian yang digunakan adalah penelitian eksperimen semu (quasi experiment designs) dengan disain non equivalent control grup dan jenis penelitian pre experimental design dengan disain one group pretest-postest[5].

Tabel 1. Desain Penelitian non equivalent control grup

\begin{tabular}{cccc}
\hline Kelas & Tes Awal & Perlakuan & Tes Akhir \\
\hline Eksperimen & $\mathrm{O} 1$ & $\mathrm{X}_{1}$ & $\mathrm{O} 2$ \\
Kontrol & $\mathrm{O} 3$ & $\mathrm{X}_{2}$ & $\mathrm{O} 4$ \\
\hline
\end{tabular}

$\mathrm{X}_{1}$ adalah pembelajaran yang menggunakan model problem solving fisika, $\mathrm{O}_{1}$ nilai ratarata pretest hasil belajar untuk kelas eksperimen, $\mathrm{O}_{2}$ nilai rata-rata posttest hasil belajar untuk kelas eksperimen, $\mathrm{X}_{2}$ adalah pembelajaran konvesional, $\mathrm{O}_{3}$ nilai rata-rata pretest hasil belajar untuk kelas kontrol dan $\mathrm{O}_{4}$ nilai rata-rata posttest hasil belajar untuk kelas kontrol.

Tabel 2. Desain Penelitian non equivalent control grup

Kelas Tes Awal Perlakuan Tes Akhir

\begin{tabular}{llll}
\hline Eksperimen & $\mathrm{O} 1$ & $\mathrm{X}_{1}$ & $\mathrm{O} 2$ \\
\hline
\end{tabular}

$\mathrm{X}$ adalah pembelajaran yang diberi model problem solving fisika, $\mathrm{O}_{1}$ nilai rata-rata pretest kemampuan pemecahan masalah untuk kelas eksperimen, $\mathrm{O}_{2}$ nilai rata-rata posttest kemampuan pemecahan masalah untuk kelas eksperimen. Soal pretest dan posttest adalah soal yang sama. 
Populasi penelitian ini seluruh siswa kelas X MIPA di MAN 1 Kota Bengkulu tahun ajaran 2017/2018. Jumlah kelas X MIPA di MAN 1 Kota Bengkulu terdiri dari 4 kelas. Sampel yang dipilih dalam penelitian ini yaitu kelas X MIPA 2 dan X MIPA 3. Kelas X MIPA 2 adalah sebagai kelas eksperimen dengan jumlah siswa 37 orang sedangkan kelas X MIPA 3 adalah sebagai kelas kontrol dengan jumlah 38 orang. Teknik pengambilan sampel yang digunakan adalah perposive sampling yaitu teknik penentuan sampel dengan pertimbangan tertentu. Prosedur yang ditempuh dalam penelitian ini meliputi tahap perencanaan, tahap pelaksanaan dan hasil. Analisis data dilakukan terhadap skor rata-rata tes akhir siswa meliputi:

\section{Uji Normalitas Distribusi Data}

Uji normalitas adalah salah satu syarat bagi prosedur dalam statistik inferensial. Uji normalitas menggunakan uji chi-kuadrat dengan taraf signifikan $\alpha=0,05$. Hipotesis untuk uji normalitas adalah sebagai berikut: 1) $\mathrm{H}_{0}$ : Data berasal dari populasi yang terdistribusi normal, 2) $\mathrm{H}_{1}$ : data tidak berasal dari populasi yang berdistribusi normal.

Dalam pengujian hipotesis diterima atau ditolak dengan membandingkan $\chi^{2}$ hitung dengan nilai kritis $\chi_{\text {tabel }}^{2}$ pada taraf signifikan $(\alpha)=5 \%$. Bila harga chi kuadrat hitung lebih kecil atau sama dengan harga chi kuadrat tabel $\left(X_{h}^{2} \leq X_{t}^{2}\right)$, maka distribusi dinyatakan normal, dan bila lebih besar (>) dinyatakan tidak normal[5].

\section{Uji Homogenitas Varian Data}

Apabila diketahui data berdistribusi normal maka langkah selanjutnya adalah melakukan uji $\chi$ homogenitas varian. Uji homogenitas dilakukan dengan menghitung statistik varians melalui perbandingan varians terbesar dengan varians terkecil antara kedua kelompok kelas sampel. Bila $F_{\text {hitung }}<\mathrm{F}_{\text {tabel }}$ maka varians dari kelompok yang dibandingkan dinyatakan tidak signifikan yang berarti bahwa varians homogeny, sebaliknya apabila koefisien $F_{\text {hitung }}$ lebih besar dari $F_{\text {tabel }}$ yang secara matematis dituliskan $F_{\text {hitung }}>F_{\text {tabel }}$ maka varians dari kelompok yang dibandingkan dinyatakan signifikan yang berarti bahwa varians tidak homogeny[6].

Uji Beda(Uji t-test)

Uji beda menggunakan uji t-test polled varian $n_{1} \neq n_{2}$. Jika harga $t_{\text {hitung }}>t_{\text {tabel }}$ dari data pretest dan posttest hasil belajar pada signifikansi $(\alpha)=5 \%$. maka terdapat perbedaan yang signifikan. Dalam pengujian hipotesis melalui data posttest hasil belajar, kriteria untuk menolak atau tidak menolak Ho berdasarkan nilai $t_{\text {tabel }}$ pada taraf signifikan $(\alpha)=5 \%$. jika $t_{\text {hitung }}>t_{\text {tabel }}$ maka Ho ditolak dan jika $t_{\text {hitung }}<t_{\text {tabel }}$ Ho tidak dapat ditolak.

\section{HASIL DAN PEMBAHASAN}

Siswa kelas eksperimen diberikan perlakukan pembelajaran dengan menerapkan model problem solving fisika. Siswa diberikan soal yang berbasis lembar kerja siswa (LKS) problem solving fisika. LKS terdapat soal dan permasalahan yang diselesaikan menggunakan langkahlangkah problem solving fisika. Tes yang diberikan pada kelas eksperimen tes hasil belajar dan kemampuan pemecahan masalah, sedangkan pada kelas kontrol menggunakan pembelajaran konvesional yang mana kelas kontrol digunakan sebagai pembanding untuk hasil belajar kelas eksperimen. Pembelajaran konvesional merupakan pembelajaran yang sering diterapkan oleh guru di suatu kelas, yang mana pembelajaran kovesional yang diterapkan di kelas kontrol merupakan pembelajaran Direct Interaction (DI).

\subsection{Hasil Belajar}

Abdurrahman (1999) hasil belajar adalah kemampuan yang diperoleh anak setelah melalui kegiatan proses pembelajaran. Sama halnya dengan Abdurrahman, Juliah (2004) juga berpendapat bahwa hasil belajar adalah segala sesuatu yang menjadi milik siswa sebagai akibat dari kegiatan belajar yang dilakukannya dalam[7]. Hasil belajar adalah hasil yang diperoleh setelah melewati proses interaksi belajar dan tindak mengajar, dari 
sisi guru proses evaluasi hasil belajar merupakan bagian akhir dari tindak mengajar sedangkan dari sisi siswa hasil belajar merupakan berakhirnya penggal dan puncak proses belajar[8].

Diperoleh rata-rata pretest hasil belajar setiap pertemuan untuk kelas eksperimen yaitu 24,$2 ; 22,1 ; 22,8$; dan dan rata-rata semua pertemuan adalah 23,1 . Untuk postest hasil belajar diperoleh nilai rata-rata yaitu 81,$3 ; 83,7 ; 86,6$ dan rata-rata semua pertemuan adalah 83,9. Data tersebut dapat dilihat pada gambar 1.

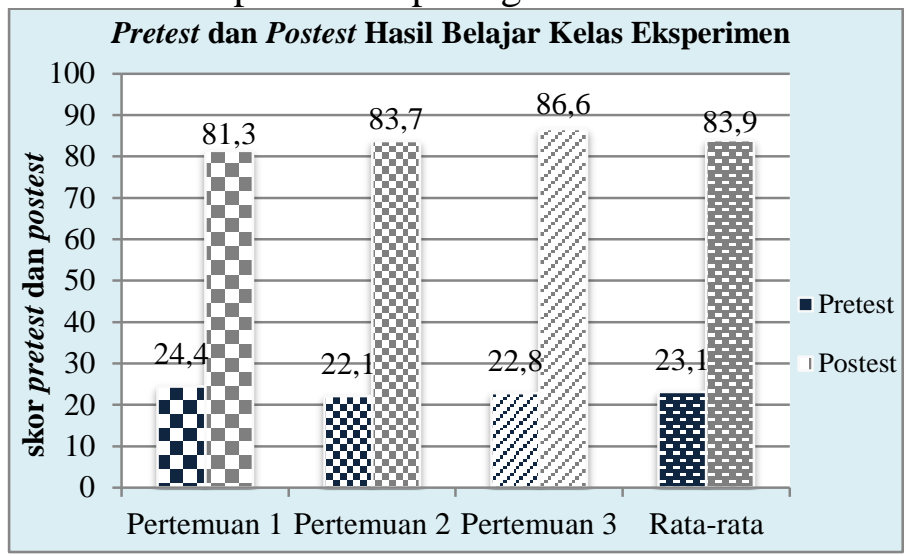

Gambar 1. Hasil Belajar Siswa Kelas Eksperimen

Kelas kontrol skor rata-rata hasil pretest setiap pertemuan yaitu 23,4; 21,6; 21,2; dan ratarata semua pertemuan adalah 22,1 . Untuk postest hasil belajar diperoleh nilai rata-rata yaitu 77,$1 ; 78,7 ; 82,4$ dan rata-rata semua pertemuan adalah 79,4. Data tersebut dapat dilihat pada gambar 2.

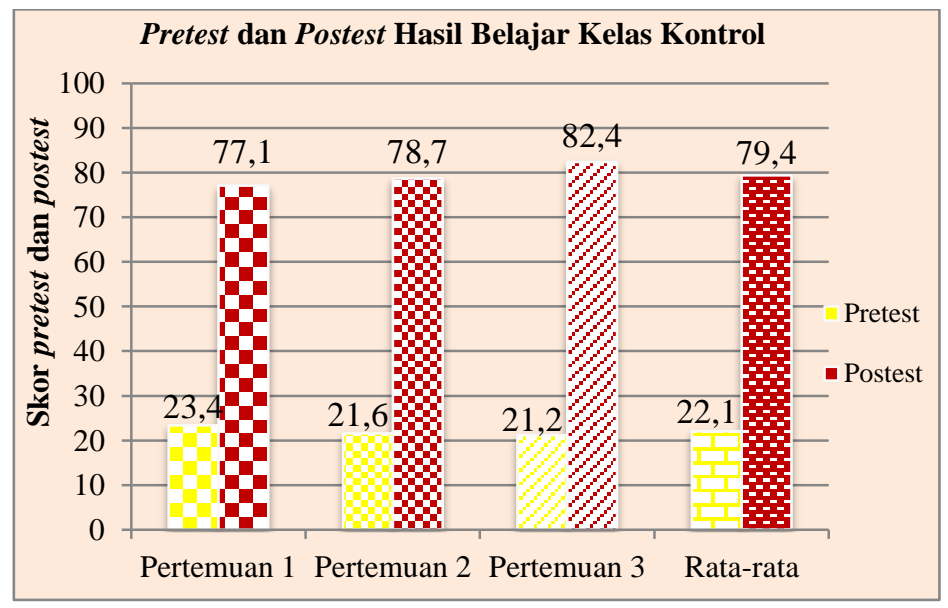

Gambar 2. Hasil Belajar Siswa Kelas Eksperimen

Hasil penelitian ini menunjukkan bahwa hasil belajar kelas eksperimen yang diberikan pembelajaran menggunakan model problem solving fisika lebih tinggi dibandingkan dengan hasil belajar siswa kelas kontrol yang menggunakan pembelajaran konvesional. Hasil penelitian ini sesuai dengan hasil penelitian yang telah dilakukan oleh Warimun (2012) yang menunjukkan bahwa pembelajaran dengan menggunakan model problem solving fisika dapat terjadi peningkatan penguasaan konsep fisika dan kemampuan problem solving mahasiswa dalam topik pembelajaran optika geometri dengan kategori tinggi.

Paradigma konstruktivistik pembelajaran lebih mengutamakan penyelesaian masalah, mengembangkan konsep, dan konstruksi solusi. Pembelajaran problem solving sendiri melatih siswa dalam pengambilan keputusan dalam pemecahan masalah. Pengambilan keputusan adalah suatu aktivitas yang berlangsung setiap saat dalam melakukan sesuatu yang mana dasarnya bahwa esensi kehidupan sehari-hari adalah situasi pemecahan masalah. Pengambilan keputusan sangat ditentukan oleh pengetahuan dan keterampilan berpikir 
seseorang.

Menurut Slameto perbedaan hasil belajar kognitif antara siswa yang belajar fisika menggunakan model problem solving fisika dan siswa yang belajar fisika melalui pembelajaran konvensional dipengaruhi juga oleh berbagai faktor, diantaranya adalah metode mengajar yang digunakan. Pembelajaran dengan pembelajaran konvensional bisa saja menghasilkan nilai yang tinggi akan tetapi hal tersebut tidak diikuti dengan adanya pengembangan kemampuan berpikir siswa dalam memecahkan masalah dan memahami konsep berdasarkan pengalaman[9].

\subsection{Kemampuan Pemecahan Masalah}

Gok (2010) kemampuan pemecahan masalah adalah kemampuan siswa yang dapat mengkontruksikan sendiri apa yang harus dikerjakan dalam suatu keadaan tertentu dengan menggunakan informasi yang ada[2]. Kemampuan seseorang untuk menemukan cara melalui suatu proses yang melibatkan pemerolehan dan pengorganisasian informasi untuk mencapai suatu tujuan[10]. Yamin (2008) menyatakan bahwa kemampuan pemecahan masalah merupakan kemampuan individu dengan megumpulkan fakta-fakta, analisis informasi, menyusun berbagai alternatif pemecahan, dan memilih pemecahan yang paling efektif untuk memecahkan suatu permasalahan dengan menggunakan proses berpikirnya[11].

Kemampuan pemecahan masalah pada penelitian ini hanya di ukur pada kelas eksperimen saja. Siswa kelas eksprimen diberikan LKS berbasis problem solving fisika, yang mana LKS tersebut berisi soal atau permasalahan dan siswa mengerjakan dengan langkah-langkah problem solving fisika.

Diperoleh skor rata-rata pretest KPM setiap pertemuan yaitu 17,69; 22,3; 25,99; dan ratarata pretest semua pertemuan adalah 22. Postest KPM diperoleh rata-rata yaitu 81,34; 86,87; 88,29 dan rata-rata semua pertemuan adalah 85,5. Data tersebut dapat dilihat pada gambar 3 .

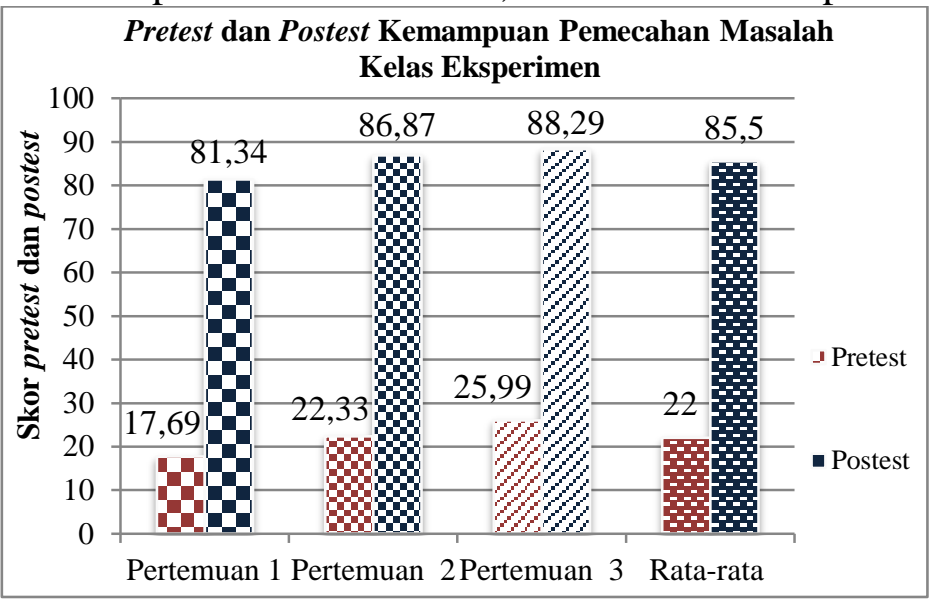

\section{Gambar 3. Rata-Rata Pretest dan Posttest KPM Kelas Eksperimen}

Kemampuan pemecahan masalah merupakan kesanggupan seseorang dalam menyelesaikan dan mencari jalan keluar dari suatu masalah. Mengembangkan kemampuan tersebut siswa tidak hanya diberi contoh saja tetapi siswa juga dibimbing agar memahami proses penyelesaian masalah dari tahap mengenali masalah, merencanakan strategi, menerapkan strategi dan mengevaluasi masalah sehingga siswa menjadi aktif dalam pemecahan masalah.

Pembelajaran menggunakan model pembelajaran problem solving fisika siswa dilatih dengan memberikan masalah yang berkaitan seputar kehidupan sehari-hari dan belajar sesuai pengalaman mereka. Siswa juga berperan aktif dalam proses pembelajaran dan secara kreatif berusaha menemukan solusi atau konsep-konsep yang diperolehnya dari permasalahan yang diajukan untuk memecahkan masalah sehingga wawasan dan daya pikir mereka berkembang dan menyadari banyak hal atau kejadian yang dapat mereka jumpai dalam kehidupan seharihari yang berkaitan dengan konsep fisika yang mereka pelajari. Siswa dapat menghasilkan 
jawaban yang lebih ilmiah, meningkatkan strategi pemecahan masalah dan pemahaman konseptual yang baik lalu membantu siswa dalam mengkonstruksikan pengetahuan baru, dan dapat mengembangkan keterampilan pemecahan masalah, sehingga memberikan kesempatan kepada siswa dalam proses pembelajaran untuk meningkatkan kemampuan pemecahan masalah.

Uji inferensial

Pada uji normalitas data menggunakan chi-kuadrat. Adapun hasil uji normalitas data pretest dan posttest hasil belajar siswa dapat dilihat pada tabel 3.

Tabel 3. Hasil perhitungan uji normalitas

\begin{tabular}{ccrrc}
\hline Kelas & Data & $\mathbf{X}^{2}{ }_{\text {hitung }}$ & $\mathbf{X}_{\text {tabel }}$ & Distribusi Data \\
\hline Kontrol & Pretest & 1,54 & 11,07 & Normal \\
& Posttest & 4,53 & 11,07 & Normal \\
Eksperimen & Pretest & 3,58 & 11,07 & Normal \\
& Posttest & 8,08 & 11,07 & Normal
\end{tabular}

Sedangkan untuk uji homogenitas varian data melalui perbandingan varian terbesar dengan varian terkecil antara kedua kelompok kelas sampel. Adapun hasil uji homogenitas varian data minat, motivasi dan hasil belajar siswa dapat dilihat pada tabel 4 .

Tabel 4. Hasil perhitungan uji Homogenitas varian

\begin{tabular}{|c|c|c|c|c|c|c|c|c|c|c|}
\hline Kelas & $\mathbf{N}$ & Pretest & Varian & SD & $\mathbf{F}_{\text {Hitung }}$ & Posttest & Varian & SD & $\mathbf{F}_{\text {Hitung }}$ & $\mathbf{F}_{\text {Tabel }}$ \\
\hline Kontrol & 38 & 22,1 & 19 & 4,4 & \multirow{2}{*}{1,02} & 79,4 & 56,9 & 7,5 & \multirow{3}{*}{1,16} & \multirow{4}{*}{1,73} \\
\hline Eksperimen & 37 & 23,1 & 18,6 & 4,3 & & 83,9 & 66,1 & 8,1 & & \\
\hline Syara & & \multirow{2}{*}{\multicolumn{4}{|c|}{$\mathbf{F}_{\text {Hitung }}<\mathbf{F}_{\text {Tabel }}$}} & \multirow{2}{*}{\multicolumn{4}{|c|}{$\mathbf{F}_{\text {Hitung }}<\mathbf{F}_{\text {Tabel }}$}} & \\
\hline Kesimpu & & & Homo & & & & & & & \\
\hline
\end{tabular}

Uji hipotesis

Data posttest dianalisis untuk pengujian hipotesis menggunakan statistik parametrik dengan uji-t dua sampel independen dengan rumus $t$-test polled varian. Data posttest hasil belajar di peroleh bahwa $t_{\text {hitung }}$ lebih besar daripada $t_{\text {tabel }}$ pada derajat kebebasan (dk) sama dengan 73 dan taraf signifikansi 5\% sebesar 1,99 atau ditulis 2,47>1,99 sehingga $\mathrm{H}_{0}$ ditolak atau dengan kata lain $\mathrm{H}_{\mathrm{a}}$ diterima artinya bahwa posttest hasil belajar dari kedua sampel setelah diberi perlakuan terdapat perbedaan secara signifikan. Hasil uji $\mathrm{t}$ data posttest tersebut menunjukkan bahwa siswa yang diberi pembelajaran menggunakan model problem solving fisika pada kelas eksperimen memiliki nilai yang berbeda dengan nilai siswa yang menggunakan pembelajaran konvesional.

Tabel 5. Uji-T Hasil Belajar Siswa

\begin{tabular}{|c|c|c|c|c|c|c|}
\hline Hasil & Kelas & $\mathbf{N}$ & $\begin{array}{c}\text { Rata- } \\
\text { rata }\end{array}$ & $\mathbf{t}_{\text {hitung }}$ & $\begin{array}{c}\mathbf{t}_{\text {tabel }}(\mathrm{dk} \\
=73) \text { taraf } \\
\text { kesalahan } \\
5 \%\end{array}$ & Kesimpulan \\
\hline \multirow{2}{*}{$\begin{array}{c}\text { Pretest Hasil } \\
\text { Belajar }\end{array}$} & Kontrol & 38 & 22,1 & \multirow{2}{*}{1,03} & & TIDAK \\
\hline & Eksperimen & 37 & 23,1 & & & $\begin{array}{l}\text { TERDAPAT } \\
\text { PERBEDAAN }\end{array}$ \\
\hline \multirow{2}{*}{$\begin{array}{c}\text { Posttest } \\
\text { Hasil } \\
\text { Belajar }\end{array}$} & Kontrol & 38 & 79,4 & \multirow{2}{*}{2,47} & \multirow{2}{*}{1,99} & TERDAPAT \\
\hline & Eksperimen & 37 & 83,9 & & & PERBEDAAN \\
\hline
\end{tabular}

Maka karena thitung > tabel pada taraf signifikan $(\alpha=0,05)$ maka terdapat perbedaan. Dapat disimpulkan bahwa terdapat pengaruh model pembelajaran problem solving fisika terhadap hasil belajar kelas X MIPA MAN 1 Kota Bengkulu.

Analisis Deskriptif Kemampuan Pemecahan Masalah

Rata-rata skor pretest KPM didapatkan sebesar 22 dan rata-rata skor posttest sebesar 85,5. Untuk mengetahui ada atau tidaknya pengaruh kemampuan pemecahan kelas sebelum dan sesudah diberi perlakuan diperoleh dari nilai rata-rata posttest kemampuan pemecahan kelas 
eksperimen dikurang dengan nilai rata-rata pretest kemampuan pemecahan kelas eksperimen atau dapat ditulis dengan $\mathrm{O}_{2}-\mathrm{O}_{1}(85,5-22)$ menghasilkan 63,5, sehingga disimpulkan terdapat pengaruh pembelajaran problem solving fisika terhadap kemampuan pemecahan masalah fisika setelah diberikan perlakuan ${ }^{[5]}$.

Tabel 6. Data Pretest dan Postest KPM Kelas Eksperimen

\begin{tabular}{ccccc}
\hline Hasil & Kelas & N & Rata-rata & Pengaruh $\left(\mathbf{O}_{2}-\mathbf{O}_{1}\right)$ \\
\hline $\begin{array}{l}\text { Pretest } \text { KPM }\left(\mathbf{O}_{1}\right) \\
\text { Postest KPM }\left(\mathbf{O}_{2}\right)\end{array}$ & Eksperimen & 37 & 22 & 63,5 \\
\hline
\end{tabular}

\section{KESIMPULAN DAN SARAN \\ 4.1 KESIMPULAN}

Terdapat pengaruh pembelajaran yang menggunakan model problem solving fisika terhadap hasil belajar dan kemampuan pemecahan masalah siswa pada konsep Usaha dan Energi. Data yang telah diperoleh menunjukkan bahwa hasil belajar siswa yang diajarkan menggunakan model problem solving fisika lebih tinggi dibandingkan dengan hasil belajar siswa yang diajarkan menggunakan pembelajaran konvesional. Berdasarkan hasil pengujian hipotesis, $t_{\text {hitung }}>t_{\text {tabel }}(2,47>2)$ terbukti bahwa hipotesis alternatif (Ha) yang diajukan secara signifikan dapat diterima. Data yang diperoleh dari hasil analisis deskriptif kemampuan pemecahan masalah yaitu (posttest - pretest) atau (85,50 - 20) sebesar 63,50, sehingga dapat disimpulkan bahwa ada pengaruh pembelajaran yang menggunakan model pembelajarn problem solving fisika terhadap kemampuan pemecahan masalah.

\subsection{SARAN}

Penelitian ini hanya dilakukan pada satu pokok bahasan saja yaitu Usaha dan Energi, maka diharapkan penelitian serupa dapat dilaksanakan pada pokok bahasan lain. Sehingga bisa mengukur sejauh mana keefektifan penggunaan model problem solving fisika. Hendaknya pembelajaran fisika menggunakan model pembelajaran problem solving fisika karena model ini bisa digunakan untuk pemberajaran berbasis eksperirnen maupun simulasi sesuai dengan karakteristik materi fisika agar siswa dapat melihat fenomena alam yang terjadi..

\section{UCAPAN TERIMAKASIH}

Ucapan terimakasih disampaikan kepada dosen pembimbing yang telah membantu dalam penelitian ini dan siswa kelas X MIPA 2 dan X MIPA 3 tahun akademik 2017/2018 sebagai subjek penelitian.

\section{DAFTAR PUSTAKA}

[1] Warimun, E. S. (2012). Penerapan Model Pembelajaran Problem Solving Fisika Pada pembelajaran Topik Optika Pada Mahasiswa Pendidikan Fisika. Jurnal Exacta, x(2), 111114.

[2] Azizah, R. Y. (2016). Kemampuan Pemecahan Masalah Melalui Pembelajaran Interactive Demonstration Siswa Kelas X SMA pada Materi Kalor. Jurnal Pendidikan Fisika dan Teknologi, II(2), 55-60.

[3] Maemanah, S. (2013). Pengaruh Pembelajaran dengan Pendekatan Kontekstual Terhadap Kemampuan Memecahkan Masalah Fisika Pada Siswa Kelas X SMA. Jurnal Pendidikan Fisika Tadulako (JPFT), 4(1), 53-60.

[4] Warimun, E. S. (2010). Model Pembelajaran Problem Solving Sebagai Alternatif Pembelajaran Fisika. Prosiding Seminar Nasional Pendidikan MIPA, 51-65.

[5] Sugiyono. (2010). Metode Penelitian Pendidikan. Bandung: Alfabeta.

[6] Widiyanto, M. A. (2013). Statistika Terapan ( Konsep dan Aplikasi SPSS). Jakarta: Elex Media Komputindo. 
[7] Jihad dan Haris. (2012). Evaluasi Pembelajaran. Yogyakarta: Multi Pressindo.

[8] Dimyati dan Mudjiono. (2015). Belajar dan Pembelajaran. Jakarta: Rineka Cipta.

[9] Purwanto, A. (2012). Kemampuan Berpikir Logis Siswa SMA 8 Kota Bengkulu dengan Menerapkan Model Inkuiri Terbimbing dalam Pembelajaran Fisika. Jurnal Exacta, X(2), 133-135.

[10] Santrock, J. W. (2013). Psikologi Pendidikan. Jakarta: Kencana Prenada Media Group.

[11] Suma, K. D. (2014). Pengaruh Model Poblem Based Learning Terhadap Kemampuan Pemecahan Masalah Fisika Melalui Pengendalian Bakat Numerik Siswa SMP. Program Pascasarjana Universitas Pendidikan Ganesha, IV, 136-142. 